\title{
Spatial Divisions and Fertility in India
}

\author{
Vijayan Pillai and Mashooq Salehin \\ School of Social Work, University of Texas at Arlington, 211 South Cooper Street, Arlington, TX 76019, USA \\ Correspondence should be addressed to Vijayan Pillai, drpillai@yahoo.com
}

Received 27 November 2011; Revised 22 April 2012; Accepted 24 April 2012

Academic Editor: Syed Masud Ahmed

Copyright ( $\odot 2012$ V. Pillai and M. Salehin. This is an open access article distributed under the Creative Commons Attribution License, which permits unrestricted use, distribution, and reproduction in any medium, provided the original work is properly cited.

\begin{abstract}
The Indian subcontinent can be divided into four geographical divisions. In this paper, we characterize three of the four divisions; the Northern Plains, the Deccan Plateau, and the Northern Mountains or the Himalayan as regions with dissimilar climatic and physical resources. It is argued that human adaptations to these variations would be varied by differences in social organization of production and consumption resulting in differences in fertility differences across the three divisions. We found significant differences in the median age at motherhood as well as in the total family size. The effects of the three selected fertility determinants, age at marriage, years of woman's education, and level of child loss on family size also varied significantly across the three divisions. There is considerable homogeneity with respect to fertility levels within the zones considered in this study.
\end{abstract}

\section{Introduction}

The purpose of this paper is to explore the relationship between broad features of the Indian geographical terrains in which populations live and their fertility. While it is wellknown that the Indian subcontinent can be partitioned into four broad types of geographical areas, very few studies have attempted to explore the relationship if any between the geographical area and fertility. Information on the broad association between geographical environment and fertility is necessary in many respects [1-3] and has policy implications.

\section{Background}

Studies on the spatial aspects of fertility in India point to the existence of a variety of patterns. The cultural, economic, and social determinants contributing to the evolution of various patterns have not been adequately identified. The cultural theory presented by Dyson and Moore [4] suggests a NorthSouth divide in fertility levels. They identify and relate the roles of several cultural aspects of property rights, ties to natal kin, and marriage rules to high-fertility levels in the North compared to the South. Marriage rules in the North are exogamic giving rise to strong patriarchal institutions that encourage high-fertility levels.
Using the 1991 Census and National Family Health Survey 1991-1993 survey data, M. L. Brookins and O. L. Brookins [5] found that seventy percent of the interstate variations in fertility in India is explained by economic variables. They also found a number of significant non-economic fertility determinants to conclude that "evidence from our study indicates that a consideration of factors determining fertilitydecision making in India must be comprehensive and extend beyond the economic factors" (p. 17).

Jeffrey [6] attributes the North-South divide to proactive policies supportive of gender equality in the South. In reexamining the Dyson and Moore [4], North-South fertility divide thesis, Rahman and Rao [7] find inadequate empirical support for the cultural factors recognized by Dyson and Moore. They assert that "it is now possible to say that recent data gathered from these two states are inconsistent with the conclusions of Dyson and Moore regarding the impact of kinship structures on women's autonomy" (p. 261).

Furthermore a few economists and anthropologists claim that interstate variations in autonomy and fertility levels stem from differences in economic development across states [8]. More specifically they point out that rice cultivation in many southern states is labor extensive requiring far more labor input than wheat cultivation in the North. This excess demand for labor is supplied by household women 
increasing their status in the family. Thus, lower fertility in the south appears to be a function of the ecological aspects of sustenance. However, ecological studies on fertility levels in India are few and far between. This study is an attempt at utilizing an ecological perspective on fertility in India. Fertility is influenced by ecological constraints on sustenance activities of the population [9]. Physical geographic divisions that are broadly associated with ecological resources and constraints, often manifest in the various combinations of climatic, soil and accessibility conditions, and dictate variations in the modes of production [10]. Studies have pointed out that a sizeable proportion of the population in India today lack of access to natural resources like land, partially imposed by geographic and physical conditions [11]. The impact of the ecological constraints on fertility in India requires analysis at the small area level. This is because access to resources for sustenance such as land is likely to vary widely [12]. However, examining the impact of large geographical and physical divisions in fertility is likely to provide preliminary evidence on the significance of this relationship.

\section{Research Questions and Theoretical Perspectives}

Ecological influences on fertility are a function of access to natural resources that are necessary to maintain a sustainable biomass-based economy [13]. From the perspective of a household, household, decreases in biomass especially in rural areas increase the time and energy required to perform chores such as fetching water, gathering raw fuel to produce goods and services for household consumption, and also to maintain live stock if desired [14]. With the depletion of the natural environment and changes in land management regulations and controls, access to basic inputs for survival of the household is likely to influence fertility $[15,16]$. Even when public policies result in the large-scale agricultural investments, the outcomes are likely to differ across geographical divisions [17, 18].

The Indian mainland has been broadly divided into four geographical areas: the Northern Mountains or the Himalayan region; the great Northern Plains; the Deccan Peninsula; the coastal plains and Islands. The Himalayan region is composed of states such as Jammu and Kashmir, Himachal Pradesh, Sikkim, and parts of Assam [19]. The Great Plains are made up of the basins of three large rivers, the Indus, the Ganga, and the Brahmaputra. The Deccan Peninsula covers the whole of South India including states such as Tamil Nadu, Karnataka, and Kerala. The Coastal Plains and Islands are composed of the regions that extend to the sea from the western and Eastern Ghats and the many islands in the Arabian Sea and the Bay of Bengal. In this study, the Northern Plains are composed of Punjab, Haryana, Delhi, Rajasthan, Uttar Pradesh, Bihar, Assam, West Bengal, Jharkhand, and Chattisgarh. The states constituting the Deccan Plateau are Orissa, Madhya Pradesh, Gujarat, Maharashtra, Andhra Pradesh, Karnataka, Goa, Kerala, and Tamil Nadu. The last division, the Himalayan region includes the states of Jammu and Kashmir, Himachal Pradesh, Uttaranchal, Sikkim, Arunachal Pradesh, Nagaland, Manipur, Mizoram, Tripura, and Meghalaya.

This study focuses on fertility differences in the three major geographical divisions, the Northern Plain, Himalayan region, and the Deccan Plateau. More specifically, we examine the effect of three determinants of fertility [20], age at marriage, child loss, and education on family size across the three geographical regions. In addition, we also describe the differences in the effects of age at marriage, child loss and education across the three divisions, the northern Plains, Himalayan region, and the Deccan Plateau.

The dependent variable, total family size, is strongly associated with the selected determinants: education, age at marriage, and child loss. Human capital theory proposes that increases in women's education are associated with increases in opportunity costs of having children. As opportunity costs increase with education, women are not only likely to delay child bearing but also have fewer children than women with fewer years of education [21]. Age at marriage is perhaps one of the most important predictors of family size. As women delay entry into marriage they are more likely to gain extra familial roles providing them with choices other than entry into motherhood. As age at marriage increases, total family size is likely to decrease [22]. Finally, in most developing countries, child loss is one of the most important motivations to have another child. Thus, women who lose their children are motivated to either compensate or even overcompensate for their loss by having more children [23]. In addition, two more variables, religion, and extent of wealth are also included in the model as controls. There is extensive literature on the role of wealth and religion on family size [24].

\section{Data and Methods}

Data are from the third wave of the National Family and Health Survey of India. The national population-based Indian NFHS-3 was conducted in all states during 20052006. The NFHS-3 administered questionnaires to female respondents 15-49 years old. The survey interviewed 131,596 eligible women aged 15-49 years producing a response rate of $95 \%$. Approximately 85,400 eligible men between the ages of 15 to 54 were also interviewed with a response rate of 87 percent. The questionnaires were verbally administered to male and female respondents separately. The respondent selected from a version of the questionnaire available in English or in the main language of the state of residence of the respondent. The NFHS-3 used a stratified, multistage, cluster sampling strategy to generate representative samples. Within each state, a 2-stage sampling procedure for rural areas and a 3-stage sampling procedure for urban areas identified 3850 primary sampling units (PSUs) selected using a probability proportionate to size-sampling method [25].

4.1. Variables. The dependent variable is number of living children. The variable "age at marriage" is the age at first marriage of the respondent excluding those whose married gauna was not performed. Education is measured as the 
TABLE 1: Selected determinants of total numbers of children: mean and proportions by geographical division.

\begin{tabular}{|c|c|c|c|c|c|c|}
\hline \multirow{2}{*}{ Variable } & \multicolumn{2}{|c|}{ Northern } & \multicolumn{2}{|c|}{ Deccan } & \multicolumn{2}{|c|}{ Himalayan } \\
\hline & Mean & Percentage & Mean & Percentage & Mean & Percentage \\
\hline Age of marriage (Yrs) & 17.26 & & 18.04 & & 19.14 & \\
\hline Years of schooling (Yrs) & 5.19 & & 6.63 & & 6.74 & \\
\hline Child loss & 0.18 & & 0.12 & & 0.10 & \\
\hline Hindu & & 76.76 & & 80.60 & & 50.05 \\
\hline Muslim & & 15.99 & & 11.66 & & 12.38 \\
\hline \multicolumn{7}{|l|}{ Religion } \\
\hline Christian & & 1.00 & & 5.08 & & 29.06 \\
\hline Others & & 6.27 & & 2.86 & & 8.51 \\
\hline \multicolumn{7}{|l|}{ Wealth Index } \\
\hline Poorer & & 16.95 & & 12.53 & & 12.47 \\
\hline Middle & & 16.96 & & 18.01 & & 24.51 \\
\hline Richer & & 20.56 & & 24.60 & & 28.41 \\
\hline Richest & & 28.91 & & 33.86 & & 30.65 \\
\hline Poorest & & 16.64 & & 11.22 & & 4.16 \\
\hline
\end{tabular}

number of years of schooling. The final independent variable, child loss, is the difference between children ever born and the number of living children. The control variables in the model are religion and wealth index. Three binary variables, Hindu, Muslim, and Christian measure religion. The last category used in the model as the reference includes all respondents with affiliation to the rest of the religions. A second control variable is wealth index. This is a NFHSconstructed index which uses information on 33 household assets and housing characteristics, such as ownership of consumer items, type of dwelling, source of water, and availability of electricity. Information on each of these components is combined into a single wealth index using a weighting method. The household population is divided into five groups of 20 percent each at the national level. The lowest value 1 is assigned to the poorest and the highest value of 5 to the richest. Table 1 presents means of the three determinants along with the proportion in each category of the control variables by geographical divisions. Mean age at marriage is highest in the Himalayan region followed by the Deccan Plateau. The average number of years of schooling is also highest in the Himalayan region followed very closely by the Deccan Plateau. The Himalayan region enjoys the least amount of child loss compared to the Northern Plains and the Deccan Plateau. As expected, the population is composed mostly of Hindus. The percent of Muslim is highest in the Northern Plains.

4.2. Analysis. We begin data analysis by regressing the total number of living children on the three selected determinants, age at marriage, years of schooling and child loss as well as on the control variables, wealth index, and religion. The effects of the independent variables in the proposed model were assumed to vary significantly across three geographical divisions. In order to test this assumption, new interaction variables of geographical divisions with each of three independent variables were constructed. A second model containing all the interactions of the geographical divisions with the three determinants was evaluated. All the interaction variables were found to be significant at the .05 level.

\section{Results}

Given significant interactions, we evaluated three separate models containing the three determinants and the controls. The results are presented in Table 2.

For each geographical division, the table presents the coefficients for the three determinants without controls and with controls. The direction and significance of all three variables remained stable in both regressions across the divisions. Both age at marriage and years of schooling have a significant negative effect on the total number of children as expected. Child loss is positively associated with total number of children. The magnitude of the effect of age at marriage on family size is higher in the Deccan Plateau than in the Northern and Himalayan region. The effect of years of schooling is also far greater in the Deccan Plateau than in the rest of the divisions. The effect of child loss is the least in the Deccan Plateau. These results suggest that the three geographical divisions vary in their pathways to achieve fertility decline. In the Deccan Plateau, the decline is shaped by the effects of a combination of forces of social development such as education and improvements in child survival and education. In the Himalayan region, the decline is partly due to the effect of demographic forces resulting in late age at marriage. In the Northern Plains, family size is influenced by education as well as child loss. The effects of both education and age at marriage on decline in fertility in the Northern Plains and the Himalayan region are similar.

The effect of religious affiliation on family size varied across divisions. Christians are likely to have a larger family size than the minority religions in the reference group in 
TABLE 2: Regression of total number of children on women's age at marriage, years of schooling, and child loss.

\begin{tabular}{|c|c|c|c|c|c|c|}
\hline \multirow{2}{*}{ Variables } & \multicolumn{2}{|c|}{ Northern Plain } & \multicolumn{2}{|c|}{ Decan Plateau } & \multicolumn{2}{|c|}{ Himalayan } \\
\hline & $b$ & $b$ & $b$ & $b$ & $b$ & $b$ \\
\hline Age at marriage & $-.039^{*}$ & $-.067^{*}$ & $-.049^{*}$ & $-.134^{*}$ & $-.054^{*}$ & $-.057^{*}$ \\
\hline Years of schooling & $-.114^{*}$ & $-.137^{*}$ & $-.098^{*}$ & $-.607^{*}$ & $-.116^{*}$ & $-.126^{*}$ \\
\hline Child loss & $1.270^{*}$ & $1.276^{*}$ & $0.697^{*}$ & $.169^{*}$ & $1.253^{*}$ & $1.247^{*}$ \\
\hline \multicolumn{7}{|l|}{ Controls } \\
\hline Hindu & & .051 & & $-.125^{*}$ & & .025 \\
\hline Muslim & & $.210^{*}$ & & $.101^{*}$ & & -.069 \\
\hline Christian & & .013 & & .002 & & $.272^{*}$ \\
\hline Others (refs) & & .000 & & .000 & & .000 \\
\hline Poorer & & .047 & & .021 & & .116 \\
\hline Middle & & $.092^{*}$ & & $.064^{*}$ & & $.133^{*}$ \\
\hline Richer & & $.194^{*}$ & & $.252^{*}$ & & $.173^{*}$ \\
\hline Richest & & $.585^{*}$ & & $.561^{*}$ & & $.336^{*}$ \\
\hline \multicolumn{7}{|l|}{ Poorest (refs) } \\
\hline Adjusted $R^{2}$ & .238 & .268 & .216 & .234 & .218 & .223 \\
\hline
\end{tabular}

${ }^{*} P<.05 ; b$ is unstandardized regression coefficient.

TABLE 3: T tests of the differences in women's age at marriage, years of schooling, and child loss across the three divisions of Northern Plains, Deccan Plateau, and the Himalayan Region.

\begin{tabular}{lcc}
\hline Variable & Comparison & $\begin{array}{c}\text { Difference in } \\
\text { means }\end{array}$ \\
\hline $\begin{array}{l}\text { Age at } \\
\text { marriage }\end{array}$ & Northern versus Decan* & .78 years \\
Year of & Northern versus Himalayan* & 1.88 years \\
schooling & Northern versus Decan* & 1.64 years \\
& Northern versus Himalayan* & 1.55 years \\
Child loss & Northern versus Decan* & -.054 \\
& Northern versus Himalayan* & -.073 \\
\hline$P<.05$ & &
\end{tabular}

the Himalayan regions. In the rest of the regions, it had no effect. In addition, Muslims were also likely to have larger family sizes in the Northern Plains as well as the Deccan Plateau than those in the reference group of respondents with minority religious affiliations. Surprisingly, all the wealth index variables, except the category of the "poor." are positively related to total number of children. This result underscores the importance and unwavering desire for children in Indian society even when alternatives to having children become possible with increases in wealth. The adjusted $R$ square for all the models varies between 20 and 24 percent. In addition to the significant variations found in the effects of the three variables, it is also likely that their compositions may vary across the three divisions. In order to explore this, we examine the significance of the differences in the mean levels of the three variables through paired comparisons.

Table 3 presents the results of the $t$-tests for the differences in the mean level of each of the three variables. The divisions compared for each variable are; Northern Plains against Deccan Plateau, Northern Plains, and Himalayan region. All mean differences are significant at the .05 level. Average age at marriage and means years of schooling are significantly higher in the Himalayan region compared with the Northern Plains. Furthermore, Himalayan region enjoys far less child loss in general than the rest of the divisions. Though the Himalayan region has high age at marriage as well as high average years of schooling compared to the Northern Plains, their their effects on family size are less then their familt size effects in the Deccan Pleateau. In spite of the fact that both late marriage and improvements in years of schooling are widespread in the Himalayan region, it appears that the fertility decline in Deccan Plateau is perhaps more driven by changes with respect to age at marriage and education.

We further explore the differences in family size across the divisions by examining yet one more demographic force that may shape family size. It is well known that the tempo of family building affects family size. If the pace of family formation is slow, the achieved family size is likely to be small. Postponement of marriage and delays in entry into motherhood, shortening the reproductive years available for family building, decreases the likelihood of large families. Transition to small family size is associated with postponement of marriage. Consequently, the postponement of marriage along with the current small family size in an Indian state is qualified as evidence of a strong evidence of fertility decline.

The Himalayan region has the largest median age at marriage though its difference from the Deccan median is small. In order to identify states with strong evidence of fertility decline, cutoff points for median age at marriage, and total number of children were arbitrarily fixed. The points were selected to identify areas with similar fertility levels as Kerala and Delhi. The cutoff points were set at 18 years in median age at motherhood and a family size of 1.85 children, respectively. 
TABLE 4: States with median age at marriage greater than 18 years and total family size less than 1.85 by geographical division.

\begin{tabular}{lc}
\hline Geographical division & States \\
\hline \multirow{2}{*}{$(1)$ (Northern) } & Punjab \\
& Delhi \\
& Assam \\
\hline (2) (Deccan) & Goa \\
& Kerala \\
& Tamil Nadu \\
& Maharashtra \\
\hline & Jammu \& Kashmir \\
(3) (Himalayan) & Himachal Pradesh \\
& Sikkim \\
& Manipur \\
& Meghalaya \\
\hline
\end{tabular}

Table 4 presents the list of all the Indian states with an average total family size less than 1.85 and median age at marriage greater than 18 years as estimated using the NFHS3 data. The states can be grouped into three clusters with Jammu-Kashmir, Punjab, Himachal Pradesh, and Delhi in the first; Tamil Nadu, Maharashtra, Goa, and Kerala in the second; Meghalaya, Assam, Tripura, Manipur, and Sikkim in the third. Though both Jammu-Kashmir and Himachal Pradesh were grouped under the Himalayan Zone in this study, both these states are in close proximity with Delhi and Punjab in the Northern Zone. However, though Assam is grouped under the Northern Zone, the state is situated closer to the states in the Himalayan Zone. Broadly stated, the Himalayan Zone is characterized by lower levels of fertility than the rest of the country.

\section{Conclusions}

The findings of this study may be evaluated against the background of a strong tradition of fertility research in India. Many of the pioneering studies, such as the Khanna study, focused on economic costs and benefits of having children. The focus on economic costs shifted to social development determinants with the unpredicted decline in fertility in the poor state of Kerala. The failure to identify anyone compositional variable as a significant factor in the fertility decline led to a shift in attention to diffusion processes [26, 27]. Subsequently, recent studies have examined geographical factors in fertility decline [28]. This study contributes to an understanding of the role of geographical factors in Indian fertility decline by emphasizing the ecological aspects of geography. Ecological theories take into account both the compositional as well as the contextual aspects of fertility decline. The ecological characteristics are often related to the special properties of relevant social aggregates emerging from their interactions with time and space. This study emphasized the impact of physical environment as a component of ecological effects on fertility decline. Current efforts to model contextual effects on Indian fertility decline stand to gain by the rigorous utilization of ecological theories.

This study assumed the presence of ecological zones characterized by the presence of physical attributes such as soil and climatic conditions. One limitation of this approach is that the number of zones may vary depending upon the physical attributes used for classification. For example, the Government of India has identified 15 agroecological regions on the basis of environmental characteristics such as soil type, topography, and water resources [29]. Regardless of the nature and size of the selected zones, fertility levels are certainly influenced by social, cultural, and organizational aspect. This paper has attempted to examine the gross effects of the zones on Indian fertility. Through selective inclusion of sociocultural variables associated with selected zones future studies may broaden existing socioeconomic explanations of Indian fertility.

\section{Acknowledgment}

One of the authors would like to thank Ann C Kelley for all her assistance throughout the course of development of this paper.

\section{References}

[1] M. Susser, "The logic in ecological: I. The logic of analysis," American Journal of Public Health, vol. 84, no. 5, pp. 825-829, 1994.

[2] S. Curtis and I. R. Jones, "Is there a place for geography in the analysis of health inequality?" Sociology of Health and Illness, vol. 20, no. 5, pp. 645-672, 1998.

[3] G. H. Williams, "The determinants of health: structure, context and agency," Sociology of Health and Illness, vol. 25, pp. 131-154, 2003.

[4] T. Dyson and M. Moore, "On kinship structure, female autonomy, and demographic behavior in India," Population \& Development Review, vol. 9, no. 1, pp. 35-60, 1983.

[5] M. L. Brookins and O. T. Brookins, "An exploratory analysis of fertility differentials in India," Journal of Development Studies, vol. 39, no. 2, pp. 54-72, 2002.

[6] R. Jeffrey, Politics, Women and Well-Being: How Kerala Became, "A Model", Oxford University Press, New Delhi, India, 1993.

[7] L. Rahman and V. Rao, "The determinants of gender equity in India: examining Dyson and Moore's thesis with new data," Population and Development Review, vol. 30, no. 2, pp. 239268, 2004.

[8] M. R. Rosenzweig and T. P. Schultz, "Market opportunities, genetic endowments, and intrafamily resource distribution: child survival in rural India," American Economic Review, vol. 72, no. 4, pp. 803-815, 1982.

[9] A. P. J. Mol and G. Spaargaren, "Ecological modernisation theory in debate: a review," Environmental Politics, vol. 9, no. 1, pp. 17-49, 2000.

[10] R. Walker, "The geographical organization of production-systems," Environment \& Planning D, vol. 6, no. 4, pp. 377-408, 1988.

[11] B. Fisher and T. Christopher, "Poverty and biodiversity: measuring the overlap of human poverty and the biodiversity hotspots," Ecological Economics, vol. 62, no. 1, pp. 93-101, 2007. 
[12] M. Fafchamps and F. Shilpi, "Cities and specialisation: evidence from south Asia," Economic Journal, vol. 115, no. 503, pp. 477-504, 2005.

[13] F. DeClerck, J. C. Ingram, and C. M. Rumbaitis del Rio, "The role of ecological theory and practice in poverty alleviation and environmental conservation," Frontiers in Ecology and the Environment, vol. 4, no. 10, pp. 533-540, 2006.

[14] A. Datta and S. Sinha, "Gender disparities in social well-being: an overview," Indian Journal of Gender Studies, vol. 4, no. 1, pp. 51-65, 1997.

[15] P. K. Samal, L. M. S. Palni, and D. K. Agrawal, "Ecology, ecological poverty and sustainable development in Central Himalayan region of India," International Journal of Sustainable Development and World Ecology, vol. 10, no. 2, pp. 157168, 2003.

[16] S. Fan, A. Gulati, and S. Thorat, "Investment, subsidies, and pro-poor growth in rural India," Agricultural Economics, vol. 39, no. 2, pp. 163-170, 2008.

[17] S. Fan, P. Hazell, and T. Haque, "Targeting public investments by agro-ecological zone to achieve growth and poverty alleviation goals in rural India," Food Policy, vol. 25, no. 4, pp. 411428, 2000.

[18] W. E. Rees, "An ecological economics perspective on sustainability and prospects for ending poverty," Population and Environment, vol. 24, no. 1, pp. 15-46, 2002.

[19] V. Bhasin, Habitat, Habitation and Health in the Himalayas: A Comparative Study of the People of Sikkim and the Gaddis of Himachal Pradesh, KRE Books, New Delhi, India, 1990.

[20] M. K. Bhasin and S. Nag, "A demographic profile of the people of Jammu and Kashmir: estimates, trends and differentials in fertility," Journal of Human Ecology, vol. 13, no. 1-2, pp. 57112, 2002.

[21] Z. Sathar, N. Crook, C. Callum, and S. Kazi, "Women's status and fertility change in Pakistan," Population \& Development Review, vol. 14, no. 3, pp. 415-432, 1988.

[22] G. W. Jones, "Fertility decline in Asia: the role of marriage change," Asia-Pacific Population Journal, vol. 22, no. 2, pp. 1310, 2007.

[23] A. Bhargava, "Family planning, gender differences and infant mortality: evidence from Uttar Pradesh, India," Journal of Econometrics, vol. 112, no. 1, pp. 225-240, 2003.

[24] T. B. Heaton, "Does Religion Influence Fertility in Developing Countries," Population Research and Policy Review, vol. 30, no. 3, pp. 449-465, 2011.

[25] International Institute for Population Sciences (IIPS) and Macro International, India National Family Health Survey (NFHS-3) 2005-2006, IIPS, Mumbai, India, 2007.

[26] A. M. Basu and S. Amin, "Conditioning factors for fertility decline in Bengal: history, language identity, and openness to innovations," Population and Development Review, vol. 26, no. 4, pp. 761-794, 2000.

[27] K. S. James, "Fertility decline in Andhra Pradesh: a search for alternative hypotheses," Economic and Political Weekly, vol. 34, no. 8, pp. 491-499, 1999.

[28] C. Z. Guilmoto, "The geography of fertility in India (19811991)," in Essays on Population and Space in India, C. S. Guilmoto and A. Vaguet, Eds., pp. 37-53, French Institute of Pondicherry, Pondicherry, India, 2000.

[29] P. K. R. Nair and J. C. Dagar, "An approach to developing methodologies for evaluating agroforestry systems in India," Agroforestry Systems, vol. 16, no. 1, pp. 55-81, 1991. 


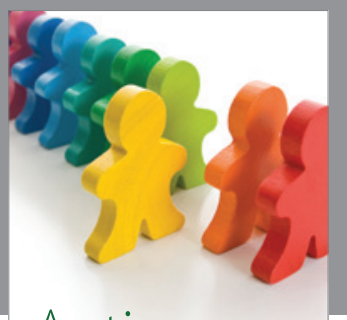

Autism

Research and Treatment
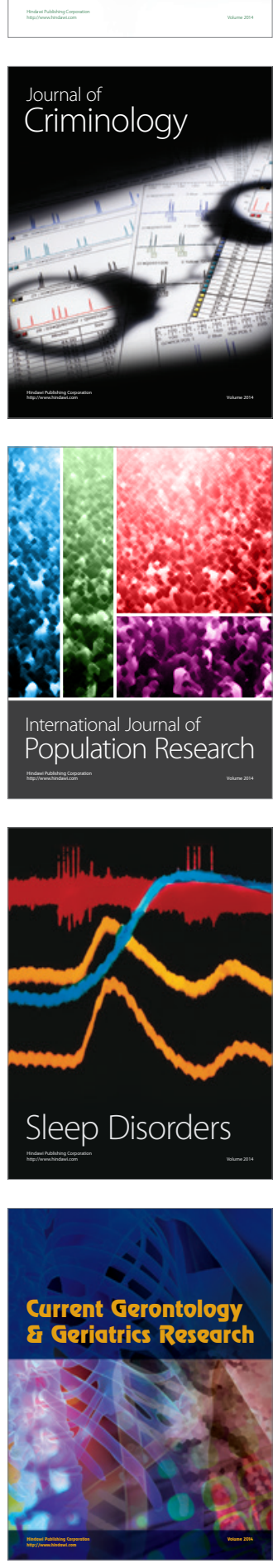
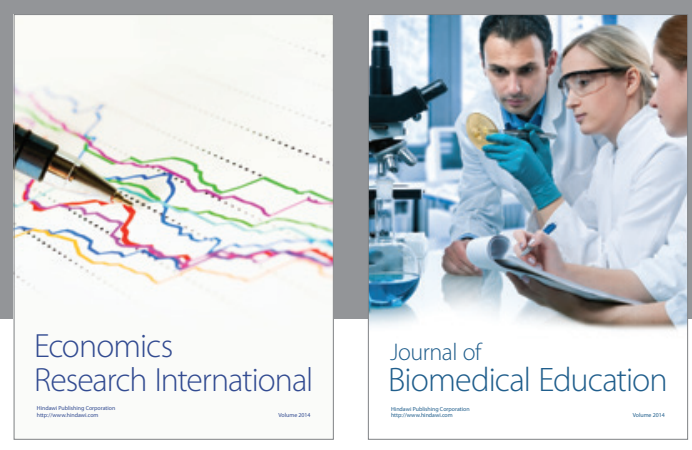

Journal of

Biomedical Education

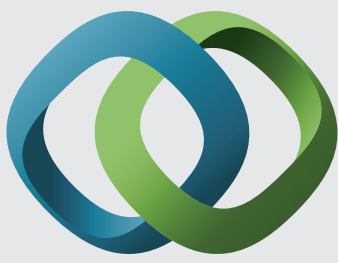

\section{Hindawi}

Submit your manuscripts at

http://www.hindawi.com
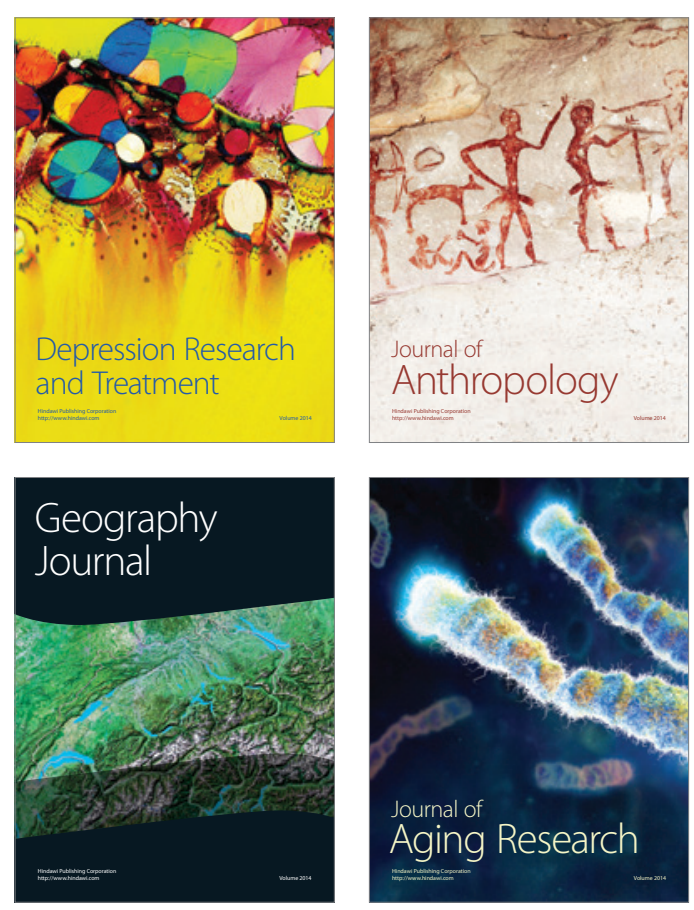

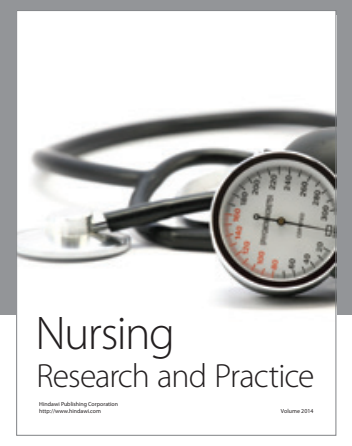

Nursing

Research and Practice

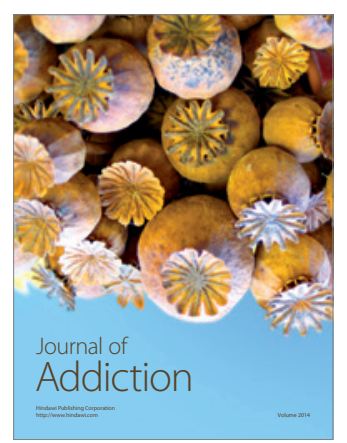

Child Development

Research

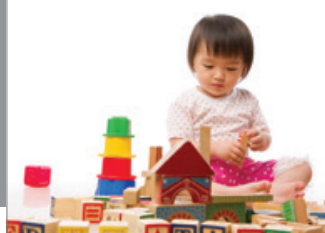

迥
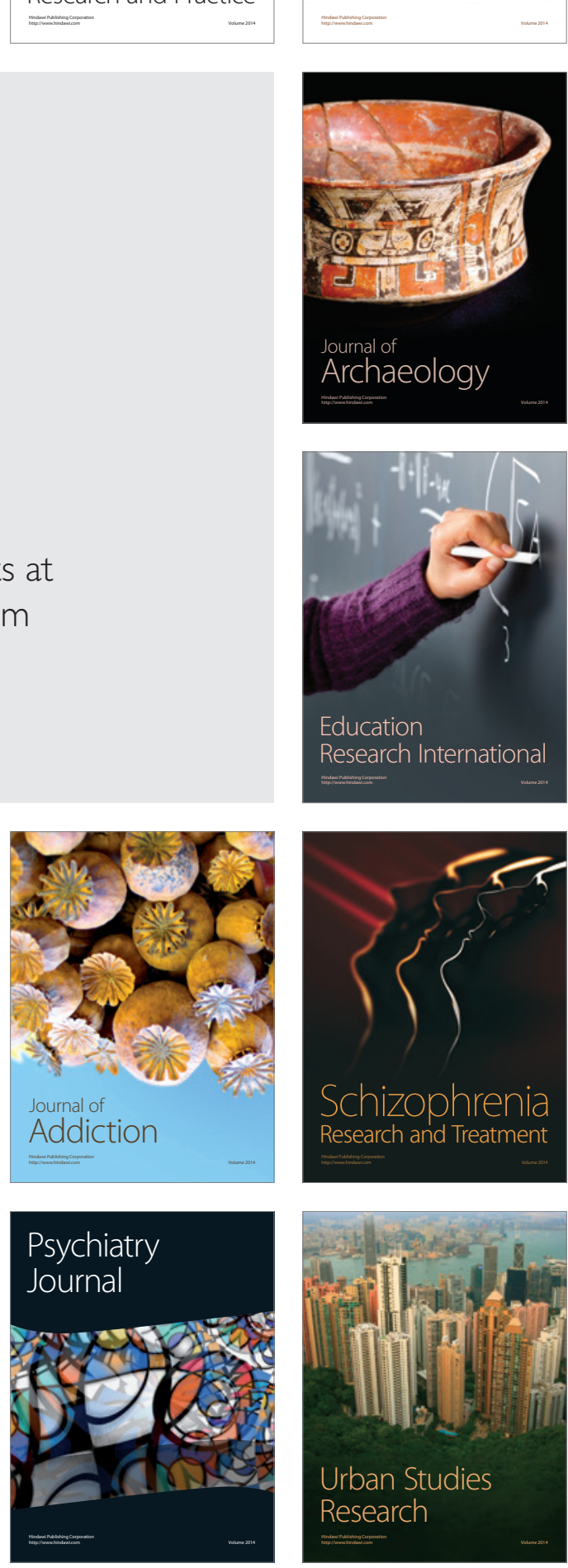